\title{
PRODUÇÃO in vitro DE EMBRIÕES DE BOVINOS DA RAÇA NELORE ORIUNDOS DE OVÓCITOS DE OVÁRIOS COM E SEM CORPO LÚTEO
}

\author{
Cristiano Pereira Barbosa ${ }^{1}$, Gilson Hélio Toniollo ${ }^{2}$, EdNALdo CARVAlHo Guimarães ${ }^{3}$
}

${ }^{1}$ Pós-graduando da Universidade Estadual Paulista, Jaboticabal, SP, Brasil - crispb@ @etsite.com.br

${ }^{2}$ Professor Doutor da Universidade Estadual Paulista, Jaboticabal, SP, Brasil

${ }^{3}$ Professor Associado, Doutor, Faculdade de Matemática - UFU - Uberlândia, MG, Brasil.

\section{RESUMO}

Comparou-se a produção de embriões a partir de ovócitos oriundos de ovários com e sem corpo lúteo de vacas da raça Nelore, em relação à qualidade e quantidade de ovócitos obtidos, embriões produzidos, taxa de prenhez e proporção dos sexos. Foram realizadas aspirações foliculares dos dois ovários de 219 vacas em 250 seções, igualmente distribuídas em cinco grupos, sendo G1=fêmeas gestantes; G2=não gestantes, com CL e submetidas a tratamento hormonal com progestágeno+BE+PGF $2 \propto ; \mathrm{G} 3=$ não gestantes, sem $\mathrm{CL}$ e com o mesmo tratamento de G2; G4=não gestantes, com presença de CL e sem tratamento; G5=não gestantes, sem presença de CL e sem tratamento. Os resultados foram avaliados pela análise de variância (ANOVA) e aplicado o Teste de Tukey para comparação entre médias, a 5\% de significância, pelo programa SISVAR. Já para comparação de proporção de sexos dentro e entre os grupos, foi utilizado o teste de comparação múltipla de proporções. O G4 produziu maior média de ovócitos totais aspirados que G2 e G3. Comparando-se os três grupos que apresentavam CL (G1, G2, G4), o G4 foi superior a G1 e G2 em ovócitos totais, no ovário com e sem CL. Em ovócitos viáveis, G2 foi superior a G1 no ovário com CL. Os ovócitos obtidos de ovários com CL é que resultaram em melhores índices de produção de embriões. As vacas gestantes produziram melhor nos ovários sem CL, com mais ovócitos viáveis $(p<0,05)$ e iguais em embriões $(p>0,05)$, em relação ao ovário com CL. As taxas de prenhez e proporção dos sexos foram semelhantes entre os grupos $(\mathrm{p}>0,05)$. A concentração de progesterona $\left(\mathrm{P}_{4}\right)$ foi diferente entre os grupos, mas não influenciou as variáveis analisadas. A utilização do tratamento hormonal não melhorou os resultados de nenhuma variável. Portanto, o melhor critério de escolha de doadoras Nelore para programas de Produção in vitro (PIV) de embriões é o conhecimento individual de cada animal ao longo das seções de aspiração folicular.

PALAVRAS-CHAVE: aspiração folicular; progesterona sérica; reprodução animal.

\section{In vitro PRODUCTION OF NELORE BOVINE EMBRYOS ORIGINATED FROM OOCYTES FROM OVARIES WITH AND WITHOUT CORPUS LUTEUM}

\section{ABSTRACT}

This study aimed to compare the quality and quantity of oocytes aspirated from ovaries containing or not corpus luteum $(\mathrm{CL})$, the development of embryos, pregnancy rate and sex ratio among embryos after IVP in Nellore cows. Follicular aspirations were performed in both ovaries of 219 cows in 250 sections, and equally divided into five groups: $\mathrm{G} 1=$ pregnant, $\mathrm{G} 2=$ not pregnant, with $\mathrm{CL}$ and submitted to hormonal therapy with
progestin+BE+PGF $F_{2 \infty} ; \mathrm{G} 3=$ not pregnant, without $\mathrm{CL}$ and with the same treatment of G2; G4 = not pregnant, with the presence of CL and no treatment; G5 = not pregnant, without the presence of $\mathrm{CL}$ and no treatment. The statistical analysis was performed with analysis of variance (ANOVA) and Tukey Test was applied to compare means at 5\% significance level, by SISVAR program. For the comparison of sex ratio within and 
between groups, the multiple comparison test of proportions was used. The G4 produced higher mean of total aspirated oocytes than G2 and G3. Comparing the three groups with CL, G4 showed higher number of oocytes than G1 and G2 in both ovaries. The G2 presented more viable oocytes than G1 in the CL-containing ovary. The ovaries without CL showed better production in pregnant cows despite of viable oocytes $(p<0.05)$, and similar embryo production $(\mathrm{p}>0.05)$ when compared with ovaries presenting CL. Oocytes obtained from ovaries with CL resulted in better rates of embryo production. Pregnancy rates and sex ratio were similar among groups $(\mathrm{p}>0.05)$. The $\mathrm{P}_{4}$ concentration was different between groups, but it did not influence any variable. The use of hormonal treatment did not improve the results of any variable. Therefore, choosing Nellore donors for IVP programs depends on knowing each animal individually along the sections of OPU.

KEYWORDS: animal reproduction; follicular aspiration; serum progesterone

\section{INTRODUÇÃO}

A produção in vitro (PIV) de embriões bovinos é uma biotécnica da reprodução que tem sido muito estudada e utilizada para o melhoramento genético do rebanho nacional. $\mathrm{O}$ interesse pela técnica de PIV cresce a cada dia, pois esse procedimento permite a recuperação de ovócitos colhidos de doadoras por meio da aspiração folicular guiada por ultra-sonografia ("Ovum Pick-up", $O P U$ ) e produção de embriões de alto valor genético, podendo ser realizada sem maiores alterações aparentes no trato reprodutivo, independente da fase do ciclo estral (BLONDIN et al., 2002).

O corpo lúteo (CL) é uma glândula endócrina que se forma no ovário, após uma ovulação, e contribui para a regulação do ciclo estral e manutenção da gestação. A principal função do CL é secretar progesterona $\left(\mathrm{P}_{4}\right)$ durante o ciclo estral bem como durante a gestação (SCHAMS \& BERISHA, 2004).

No trabalho de REIS et al. (2006), as vacas com CL apresentaram melhor desempenho que as vacas sem a presença de CL em relação às seguintes variáveis: maior número de ovócitos coletados dos dois ovários, mais ovócitos de melhor qualidade, mais zigotos que clivaram, além de produzirem, em geral, maior número de embriões aos 7 dias após a fecundação in vitro (FIV). MACHATKOVÁ et al. (1996) concluíram que ocorre maior produção in vitro de embriões quando se utilizam ovócitos aspirados durante o predomínio de CL no ciclo estral e, segundo MANJUNATHA et al. (2007), ocorrem maiores taxas de clivagem e de embriões transferíveis quando os ovócitos são provenientes de ovários onde o CL está ativo. Entretanto, MACHATKOVÁ et al. (2000) e MACHATKOVÁ et al. (2004) sugeriram que os melhores resultados em todas as etapas da PIV eram provenientes da aspiração de ovócitos durante a fase de crescimento folicular, com ausência de CL.

PFEIFER et al. (2009) verificaram que vacas tratadas com implantes de progesterona apresentaram aumento na disponibilidade de folículos na punção folicular, aumento na quantidade de ovócitos totais, na quantidade de ovócitos de melhor qualidade, na taxa de clivagem total e na produção de blastocistos, em relação às que não continham o implante. Entretanto, RAMOS et al. (2010) não encontraram vantagens em sincronizar a onda folicular de vacas doadoras para a OPU com implantes de $\mathrm{P}_{4}$ e associação de benzoato de estradiol (BE), pois observaram que não há melhorias quanto ao número e à qualidade dos ovócitos recuperados ou ao número de embriões produzidos in vitro.

Segundo TAKUMA et al. (2007), a presença de um CL local no ovário não afetou a dinâmica folicular após a aspiração folicular e nem o desenvolvimento de competente complexo cumulusovócito (COC) coletado. SUGULLE et al. (2008) concluíram que a presença de CL não influencia significativamente as taxas de clivagem e o desenvolvimento dos blastocistos produzidos in vitro.

MEINTJES et al. (1995) constataram que vacas gestantes podiam ser submetidas à técnica de aspiração folicular por via vaginal, durante o primeiro trimestre de gestação e SAUVÉ (1998), até o sexto mês de prenhez, sem que fosse notado qualquer prejuízo à gestação ou às vacas.

AVERY et al. (1991) e GUTIERREZADÁN et al. (2001) descreveram que as condições de cultivo dos embriões, associada à escolha de blastocistos de desenvolvimento mais avançado para a inovulação favoreciam os embriões de sexo masculino, por terem desenvolvimento mais rápido, em detrimento aos do sexo feminino.

Frente às contradições da literatura bem como dos trabalhos realizados a campo em programas de PIV sobre a importância do CL local e da progesterona sistêmica em doadoras de ovócitos, este trabalho objetivou verificar a influência da presença do corpo lúteo local bem como dos níveis séricos de progesterona circulante sobre a quantidade e qualidade de ovócitos aspirados por ovum pick-up (OPU), a quantidade e qualidade dos embriões, as 
taxas de concepção à inovulação e a variação do sexo destes embriões, produzidos por fecundação in vitro (FIV) em fêmeas bovinas da raça Nelore doadoras de ovócitos, gestantes ou não gestantes, e com inserção ou não de implantes de progesterona.

\section{MATERIAL E MÉTODOS}

As doadoras dos ovócitos eram da raça Nelore, todas selecionadas para produção comercial de embriões, mantidas em regime de semiconfinamento, oriundas de oito fazendas localizadas no Triângulo Mineiro, por um período de 19 meses consecutivos, com média de 13,15 seções de aspiração por mês.

Foram realizadas 250 seções de aspiração, ou seja, 500 ovários, sendo utilizadas 219 vacas, sendo que em 198 foi feita apenas uma seção e em 21 vacas foram feitas 52 seções, variando de duas a quatro seções por vaca, com intevalo mínimo de 30 dias entre elas. Os animais foram distribuídos em cinco grupos sendo: G1= fêmeas gestantes; G2= fêmeas não gestantes, submetidas à controle hormonal à base de progestágenos subcutâneos auriculares e com presença de CL; G3= fêmeas não gestantes, submetidas ao mesmo protocolo de G2 mas sem a presença de CL nos ovários; G4= fêmeas não gestantes, sem tratamento hormonal e com presença de CL nos ovários; G5= fêmeas não gestantes, sem tratamento hormonal e sem presença de CL nos ovários.

Foram realizadas 50 seções de aspiração por grupo. As idades variaram de dois a treze anos, e padronizaram-se as mesmas variações de idade em cada grupo. As vacas gestantes apresentaram média de 4,17 meses de gestação.

Os ovócitos foram aspirados pelo método de ovum pick-up (OPU), pelo fórnix vaginal. O procedimento de aspiração folicular foi realizado utilizando-se equipamento de ultrassom Aloka SSD500, com transdutor micro-convexo de 5MHZ, acoplado a guia de aspiração trans-vaginal, e as aspirações foram realizadas com agulha hipodérmica descartável 20G (Jelco Plus) e sistema de aspiração Handle Cook. A pressão de vácuo/vazão foi ajustada previamente em $18 \mathrm{~mL} /$ minuto.

As etapas da PIV foram realizadas no Laboratório Biovitro, em Uberaba, Minas Gerais. Para evitar ao máximo as variações na execução da pesquisa, a mesma equipe trabalhou em todas as etapas.

Os grupos G2 e G3 foram submetidos ao seguinte protocolo hormonal: Dia $0=$ colocação de implante de progestágeno subcutâneo auricular (Crestar® Intervet) contendo $3 \mathrm{mg}$ de Norgestomet; aplicação de $2 \mathrm{mg}$ ( $2 \mathrm{~mL}$ ) de Benzoato de Estradiol intra-muscular (IM) (Estrogin ${ }^{\circledR}, \quad$ Farmavet) e aplicação de $0,5 \mathrm{mg}$ de cloprostenol sódico $(2 \mathrm{~mL}$ de $\mathrm{PGF}_{2 \propto}$ sintética, Ciosin ${ }^{\circledR}$ MSD) (IM); Dia $5=$ retirada do implante de progestágeno e realização da OPU. Mesmo sem apresentar CL, os animais do G3 foram submetidos à aplicação de $\mathrm{PGF}_{2 \propto}$.

Nos grupos G1, G2 e G4 realizou-se a separação dos ovócitos colhidos de cada ovário, para se quantificar a produção por gônada com ou sem CL, sendo os ovócitos maturados e fecundados em placas diferentes para cada ovário.

Quinze doadoras de cada grupo (30\%) foram escolhidas aleatoriamente para se realizar coleta de sangue, via punção venosa, no momento da aspiração folicular, para a dosagem sérica de progesterona. As amostras foram centrifugadas, o soro obtido foi congelado a $-20,0^{\circ} \mathrm{C}$ e identificado quanto ao animal, grupo a que pertencia e data da coleta. O material congelado foi posteriormente analisado pelo método de quimioluminescência, com resultados registrados em nanogramas por mililitro $(\mathrm{ng} / \mathrm{mL})$.

O material aspirado foi imediatamente avaliado na própria fazenda, segundo DE LOOS et al. (1991), para contagem e seleção dos ovócitos viáveis (graus I, II e III), sendo descartados os de grau IV e desnudo.

Os ovócitos eram maturados in vitro (MIV), em meios convencionais, segundo BAVISTER et al. (1992), durante $24 \mathrm{~h}$ à temperatura de $38,5^{\circ} \mathrm{C}$ e atmosfera de $5 \%$ de $\mathrm{CO}_{2}$ em ar.

A fecundação in vitro (FIV) foi realizada após $24 \mathrm{~h}$ de MIV. O sêmen convencional congelado em palhetas de $0,25 \mathrm{~mL}$ ou $0,5 \mathrm{~mL}$ foi preparado de acordo com PARRISH et al. (1986), sendo avaliado quanto à concentração e motilidade espermática. A concentração final foi ajustada para $25 \times 10^{6}$ espermatozóides móveis/mL com meio TALP-FIV sob óleo mineral. No entanto, nos grupos G1, G2 e G4, cada dose foi dividida entre as placas com ovócitos oriundos de cada ovário, com CL e sem CL, separadamente.

Após a fecundação, os zigotos foram submetidos ao cultivo em placas de $35 \mathrm{~mm}$ com $90 \mu \mathrm{L}$ de meio SOF, cobertos com óleo mineral, atmosfera de $5 \%$ de $\mathrm{CO}_{2}$ em ar, sob umidade saturada e mantidos no interior da incubadora de cultivo à temperatura de $38,5^{\circ} \mathrm{C}$, durante sete dias (HOLM et al., 1999).

Os embriões de sete dias (blastocistos de grau I) foram envasados, individualmente, em palhetas de $0,25 \mathrm{~mL}$ em meio contendo PBS + 0,4\% de BSA (Holding Embriocare $\AA$ ). As receptoras utilizadas eram de raças mestiças de zebuínosxtaurinos, de fazendas inseridas nos 
programas do laboratório de PIV, sendo todas tratadas com o mesmo protocolo, que consistia em: Dia $0=$ colocação de implante de progestágeno subcutâneo auricular (Crestar ${ }^{\circledR}$ Intervet) contendo $3 \mathrm{mg}$ de Norgestomet; aplicação de $2 \mathrm{mg}(2 \mathrm{~mL})$ de Benzoato de Estradiol (IM) (Estrogin $\AA$, Farmavet); Dia 5 = aplicação de 300UI de eCG (Gonadotrofina Coriônica equina) (IM) (Folligon ${ }^{\circledR}$, MSD); Dia $8=$ retirada do implante de progestágeno e aplicação de $0,5 \mathrm{mg}$ de cloprostenol sódico $\left(2 \mathrm{~mL}\right.$ de $\mathrm{PGF}_{2 \propto}$ sintética, Sincrocio ${ }^{\circledR}$ Ourofino) (IM); Dia $9=$ aplicação de $1 \mathrm{mg}(1 \mathrm{~mL})$ de Benzoato de Estradiol (IM); Dia 17 = inovulação do embrião.

A inovulação foi feita pelo método nãocirúrgico, no ápice do corno uterino ipsilateral ao ovário com a presença de CL. As aspirações foliculares nas vacas doadoras foram feitas sempre no dia 9 deste protocolo de receptoras e a fecundação in vitro dos ovócitos, no dia 10.

Trinta dias após a fecundação in vitro, ou seja, 23 dias após a inovulação, foi feito o exame ultrassonográfico para diagnóstico de gestação nas receptoras. Trinta dias depois, as receptoras prenhes foram novamente avaliadas por ultrassonografia, para diagnóstico do sexo fetal.

Para as análises estatísticas, foi feita a análise de variância (ANOVA) e aplicado o teste de Tukey para comparação entre médias, a $5 \%$ de significância (SISVAR). Para comparação de proporção de sexos dentro e entre os grupos, foi utilizado o teste de comparação múltipla de proporções, utilizando-se o software $\mathrm{R}$ (2008, disponível em http://www.r-project.org/) (BIASE \& FERREIRA, 2009).

\section{RESULTADOS}

Foram aspirados 8588 ovócitos totais dos 500 ovários, das 219 vacas, em 250 seções de aspiração do experimento, resultando em uma média de 17,17 ovócitos por ovário. Os cinco grupos do experimento foram comparados da seguinte forma: todos os cinco grupos conjuntamente; os três grupos que possuíam corpo lúteo, onde se comparou o ovário com CL e o sem CL; os dois grupos que não possuíam CL e todos os grupos em relação à concentração de progesterona.

Quando se analisou estatisticamente a produção de ovócitos aspirados, observou-se que o grupo $\mathrm{G} 4$ apresentou maior média $(\mathrm{p}<0,05)$ do que os grupos G2 e G3, ficando os grupos G1 e G5 iguais a todos (Tabela 1).

Tabela 1- Médias de produção e qualidade de ovócitos, de embriões produzidos in vitro e taxa de prenhez de todos os grupos experimentais, oriundos de animais da raça Nelore

\begin{tabular}{lcccc}
\hline Grupos & $\begin{array}{c}\text { Média de Ovócitos } \\
\text { aspirados }\end{array}$ & Ovócitos viáveis $(\%)$ & Embriões viáveis $(\%)$ & Taxa de Prenhez $(\%)$ \\
\hline G1 & $31,34( \pm 20,20)$ ab & $80,29( \pm 12,40) \mathrm{a}$ & $38,51( \pm 21,70) \mathrm{a}$ & $30,81( \pm 24,88) \mathrm{a}$ \\
G2 & $29,40( \pm 20,33) \mathrm{a}$ & $82,16( \pm 11,85) \mathrm{a}$ & $36,17( \pm 21,06) \mathrm{a}$ & $36,48( \pm 26,66) \mathrm{a}$ \\
G3 & $26,58( \pm 21,24) \mathrm{a}$ & $78,27( \pm 17,36) \mathrm{a}$ & $29,49( \pm 22,61) \mathrm{a}$ & $37,93( \pm 30,79) \mathrm{a}$ \\
G4 & $44,08( \pm 32,98) \mathrm{b}$ & $81,02( \pm 11,78) \mathrm{a}$ & $32,00( \pm 20,84) \mathrm{a}$ & $32,92( \pm 28,23) \mathrm{a}$ \\
G5 & $40,36( \pm 34,25) \mathrm{ab}$ & $83,39( \pm 11,28) \mathrm{a}$ & $29,64( \pm 19,39) \mathrm{a}$ & $35,20( \pm 29,21) \mathrm{a}$ \\
$\mathrm{CV}(\%)$ & 77,39 & 16,20 & 63,77 & 80,86
\end{tabular}

Médias seguidas de letras iguais nas colunas não diferem entre si pelo teste de Tukey com 5\% de significância.

$\mathrm{CV}=$ Coeficiente de Variação.

Ao se comparar a porcentagem de ovócitos viáveis para serem maturados e fecundados, a taxa de embriões considerados viáveis para a inovulação, ou seja, embriões de grau I e a taxa de prenhez aos 30 dias de gestação, os grupos não apresentaram diferença significativa $(\mathrm{p}>0,05)$.

Os grupos G1, G2 e G4, que apresentavam CL em um dos ovários, foram analisados para se verificar a influência da presença local do CL sobre a produção dos ovários separadamente.

O grupo G4 produziu maior número $(p<0,05)$ de ovócitos recuperados nos ovários com e sem CL, bem como na somatória dos dois ovários, quando comparado com os grupos G1 e G2 (Tabela 2). Porém, quando se comparou dentro de cada grupo, os ovários com CL e sem CL forneceram 
quantidades iguais de ovócitos aspirados (p>0,05). A presença de CL em um dos ovários não propiciou diferença $(p>0,05)$ na quantidade de ovócitos aspirados para cada grupo individualmente $(16,94 \mathrm{vs}$ $18,00)$.

Tabela 2- Médias de ovócitos totais e viáveis aspirados do ovário com CL, do ovário sem CL e dos dois ovários, nos grupos G1, G2 e G4

\begin{tabular}{lcccccc}
\hline Grupos & $\begin{array}{c}\text { Média de } \\
\text { ovócitos } \\
\text { totais } \\
\text { aspirados }\end{array}$ & $\begin{array}{c}\text { Média de } \\
\text { ovócitos totais } \\
\text { de ovários } \\
- \text { com CL }\end{array}$ & $\begin{array}{c}\text { Média de } \\
\text { ovócitos totais } \\
\text { de ovários } \\
- \text { sem CL }\end{array}$ & $\begin{array}{c}\text { Ovócitos } \\
\text { viáveis }(\%)\end{array}$ & $\begin{array}{c}\text { Ovócitos } \\
\text { viáveis }- \\
\text { com CL } \\
(\%)\end{array}$ & $\begin{array}{c}\text { Ovócitos } \\
\text { viáveis }- \\
\text { sem CL } \\
(\%)\end{array}$ \\
\hline G1 & $15,67 \mathrm{a}$ & $15,04 \mathrm{a}, \mathrm{A}$ & $16,30 \mathrm{a}, \mathrm{A}$ & $79,92 \mathrm{a}$ & $77,03 \mathrm{a}, \mathrm{A}$ & $82,82 \mathrm{a}, \mathrm{B}$ \\
$\mathrm{G} 2$ & $14,70 \mathrm{a}$ & $14,06 \mathrm{a}, \mathrm{A}$ & $15,34 \mathrm{a}, \mathrm{A}$ & $82,30 \mathrm{a}$ & $84,90 \mathrm{~b}, \mathrm{~A}$ & $79,71 \mathrm{a}, \mathrm{A}$ \\
$\mathrm{G} 4$ & $22,04 \mathrm{~b}$ & $21,72 \mathrm{~b}, \mathrm{~A}$ & $22,36 \mathrm{~b}, \mathrm{~A}$ & $81,18 \mathrm{a}$ & $82,16 \mathrm{ab}, \mathrm{A}$ & $80,20 \mathrm{a}, \mathrm{A}$ \\
$\mathrm{CV}(\%)$ & 72,89 & & & $81,36 \mathrm{x}$ & & \\
\hline Ovários & $16,94 \mathrm{x}$ & & & & & \\
com CL & & & $80,91 \mathrm{x}$ & & \\
Ovários & $18,00 \mathrm{x}$ & & & & & \\
sem CL & & & & & & \\
\hline
\end{tabular}

Médias seguidas de letras iguais minúsculas nas colunas e maiúsculas nas linhas não diferem entre si pelo teste de Tukey com 5\% de significância.

$\mathrm{CV}=$ Coeficiente de Variação.

Em relação aos ovócitos viáveis para a fecundação, os três grupos foram similares na produção total; no entanto, o G2 produziu maior porcentagem do ovário com a presença de CL do que G1, sendo G4 igual aos outros dois grupos. Ao se analisar dentro de cada grupo individualmente, apenas no G1 é que houve diferença entre os dois ovários, sendo que o ovário sem CL produziu mais ovócitos viáveis que o ovário com CL (Tabela 2).

Analisando-se a porcentagem de embriões grau I (de melhor qualidade) produzidos a partir dos ovócitos colocados para a fecundação, observou-se 3 que nesses três grupos a presença de CL em um dos ovários propiciou maior produção de embriões $(40,93 \%$ vs $31,63 \%, \mathrm{p}<0,05)$ (Tabela 3$)$.

Tabela 3- Médias das taxas de embriões viáveis produzidos in vitro, originários de ovócitos do ovário com CL, do ovário sem CL e dos dois ovários, nos grupos G1, G2 e G4

\begin{tabular}{lccc}
\hline Grupos & $\begin{array}{c}\text { Embriões viáveis } \\
(\%)\end{array}$ & $\begin{array}{c}\text { Embriões viáveis - com } \\
\text { CL }(\%)\end{array}$ & $\begin{array}{c}\text { Embriões viáveis - sem CL } \\
(\%)\end{array}$ \\
\hline $\mathrm{G} 1$ & $39,93 \mathrm{a}$ & $42,44( \pm 24,50) \mathrm{a}, \mathrm{A}$ & $37,42( \pm 27,58) \mathrm{a}, \mathrm{A}$ \\
$\mathrm{G} 2$ & $36,50 \mathrm{a}$ & $41,33( \pm 24,98) \mathrm{a}, \mathrm{A}$ & $31,67( \pm 20,89) \mathrm{ab}, \mathrm{B}$ \\
$\mathrm{G} 4$ & $32,41 \mathrm{a}$ & $39,01( \pm 26,48) \mathrm{a}, \mathrm{A}$ & $25,80( \pm 19,99) \mathrm{b}, \mathrm{B}$ \\
$\mathrm{CV}(\%)$ & 66,79 & & \\
\hline Ovários com CL & $40,93 \mathrm{x}$ & \\
Ovários sem CL & $31,63 \mathrm{y}$ & \\
\hline Médias seguidas de letras iguais minúsculas nas colunas e maiúsculas nas linhas não diferem entre si pelo teste de Tukey com 5\% de \\
significância. \\
CV = Coeficiente de Variação.
\end{tabular}

Analisando-se os três grupos em conjunto, observou-se que os ovários com CL produziram porcentagens de embriões similares entre os grupos ( $\mathrm{p}>0,05)$, o que não ocorreu nos ovários sem CL, onde o G1 $(37,42 \%)$ produziu maior porcentagem $(\mathrm{p}<0,05)$ de embriões do que G4 $(25,80 \%)$, enquanto
G2 $(31,67 \%)$ produziu quantidades iguais aos outros dois grupos $(\mathrm{p}>0,05)$ (Tabela 3$)$.

Avaliando-se os grupos individualmente, nos grupos G2 e G4 os ovários com CL $(41,33 \%$ e $39,01 \%)$ produziram mais embriões $(\mathrm{p}<0,05)$ do que os ovários sem CL $(31,67 \%$ e $25,80 \%)$, mas no G1 
não houve diferença entre os ovários com e sem CL (p>0,05) (Tabela 3).

A taxa de prenhez não variou em nenhum grupo $(\mathrm{p}>0,05)$ e nem foi influenciada pela presença ou não do CL (Tabela 4).

Tabela 4- Médias das taxas de prenhez em receptoras inovuladas com embriões originários de ovócitos do ovário com CL, do ovário sem CL e dos dois ovários das doadoras, nos grupos G1, G2 e G4

\begin{tabular}{lccc}
\hline Grupos & Taxa de Prenhez $(\%)$ & $\begin{array}{c}\text { Taxa de Prenhez }- \text { com } \\
\text { CL }(\%)\end{array}$ & $\begin{array}{c}\text { Taxa de Prenhez }- \text { sem } \\
\text { CL }(\%)\end{array}$ \\
\hline G1 & $30,54 \mathrm{a}$ & $30,46( \pm 27,92) \mathrm{a}, \mathrm{A}$ & $30,62( \pm 27,77) \mathrm{a}, \mathrm{A}$ \\
$\mathrm{G} 2$ & $36,10 \mathrm{a}$ & $40,68( \pm 31,33) \mathrm{a}, \mathrm{A}$ & $31,50( \pm 30,32) \mathrm{a}, \mathrm{A}$ \\
$\mathrm{G} 4$ & $31,51 \mathrm{a}$ & $36,13( \pm 29,41) \mathrm{a}, \mathrm{A}$ & $26,88( \pm 29,16) \mathrm{a}, \mathrm{A}$ \\
CV $(\%)$ & 89,71 & & \\
\hline Ovários com CL & $35,76 \mathrm{x}$ & & \\
Ovários sem CL & $29,67 \mathrm{x}$ & & \\
\hline
\end{tabular}

Médias seguidas de letras iguais minúsculas nas colunas e maiúsculas nas linhas não diferem entre si pelo teste de Tukey com $5 \%$ de significância.

CV = Coeficiente de Variação.

Tabela 5- Proporção dos sexos de fetos originários das prenhezes do ovário com CL e do ovário sem CL das doadoras dos grupos G1, G2 e G4.

\begin{tabular}{llll}
\hline Grupos & Fêmeas & Machos & Total de prenhez aos 60 dias \\
\hline G1 com CL & $36(53,73 \%)$ a,A & $31(46,27 \%)$ a,A & 67 \\
G1 sem CL & $37(53,62 \%)$ a,A & $32(46,38 \%)$ a,A & 69 \\
G2 com CL & $47(46,53 \%)$ a,A & $54(53,47 \%)$ a,A & 101 \\
G2 sem CL & $31(46,27 \%)$ a,A & $36(53,73 \%)$ a,A & 67 \\
G4 com CL & $71(55,47 \%)$ a,A & $57(44,53 \%)$ a,A & 128 \\
G4 sem CL & $43(51,81 \%)$ a,A & $40(48,19 \%)$ a,A & 83 \\
\hline
\end{tabular}

Médias seguidas de letras iguais minúsculas nas colunas e maiúsculas nas linha, não diferem entre si pelo teste de comparação múltipla de proporções, com 5\% de significância.

Em relação ao sexo dos fetos, considerandose a produção dos ovários com e sem CL, os grupos G1, G2 e G4 (Tabela 5) não apresentaram diferenças na proporção de fetos do sexo feminino e masculino, tanto entre os grupos como dentro de cada grupo $(\mathrm{p}>0,05)$.

Quanto à proporção do sexo fetal avaliada neste trabalho, observou-se que a produção de fêmeas e de machos foi semelhante $(p>0,05)$ tanto entre os cinco grupos como dentro dos grupos, com uma média de 52,35\% de fêmeas e $47,65 \%$ de machos.

Os grupos G3 e G5 que não possuíam CL em nenhum dos ovários no dia da aspiração ou no dia da colocação do implante apresentaram algumas diferenças. Os animais do grupo G3 foram estimulados com protocolo hormonal à base de progestágeno, mas mesmo assim não obtiveram maior concentração de $\mathrm{P}_{4}$ sérica (Tabela 7) e ainda produziram menos ovócitos totais, representando menor recrutamento folicular (Tabela 6).

Para a análise da concentração sérica de $\mathrm{P}_{4}$, foram obtidos os dados de $30 \%$ dos animais de cada grupo, num total de 15 vacas, escolhidas aleatoriamente antes das coletas, a fim de identificar se houve influência dos níveis séricos de progesterona sobre as variáveis analisadas neste trabalho (Tabela 7).

O grupo G1, de vacas gestantes, apresentou a maior concentração sérica de progesterona com média de $18,47 \mathrm{ng} / \mathrm{mL}$. A média da idade gestacional dessas 15 vacas selecionadas para análise de $\mathrm{P}_{4}$ foi de 3,4 meses. O grupo G4, que se caracterizou pela presença de CL em vacas vazias e cíclicas, sem serem submetidas ao protocolo de sincronização de estro, apresentou a segunda maior concentração sérica com 8,40ng/mL. Já os grupos G2, G3 e G5 apresentaram igualmente as menores concentrações de $\mathrm{P}_{4}$, provavelmente devido à luteólise promovida no G2 e à ausência de CL no G3 e no G5. Mesmo se 
considerando as diferentes concentrações de animais avaliados ela não exerceu diferença em progesterona entre os grupos, verificou-se que nestes nenhuma das variáveis (Tabela 7).

Tabela 6- Médias de produção e qualidade de ovócitose embriões e taxa de prenhez dos grupos G3 e G5

\begin{tabular}{lcccc}
\hline Grupos & $\begin{array}{c}\text { Média de ovócitos } \\
\text { aspirados }\end{array}$ & $\begin{array}{c}\text { Ovócitos viáveis } \\
(\%)\end{array}$ & $\begin{array}{c}\text { Embriões viáveis } \\
(\%)\end{array}$ & $\begin{array}{c}\text { Taxa de Prenhez } \\
(\%)\end{array}$ \\
\hline G3 & $26,58( \pm 21,24) \mathrm{a}$ & $78,27( \pm 17,36) \mathrm{a}$ & $29,49( \pm 22,61) \mathrm{a}$ & $37,93( \pm 30,79) \mathrm{a}$ \\
G5 & $40,36( \pm 34,25) \mathrm{b}$ & $83,39( \pm 11,28) \mathrm{a}$ & $29,64( \pm 19,39) \mathrm{a}$ & $35,20( \pm 29,21) \mathrm{a}$ \\
CV $(\%)$ & 85,15 & 18,11 & 71,25 & 82,08 \\
\hline
\end{tabular}

Médias seguidas de letras iguais nas colunas não diferem entre si pelo teste de Tukey com 5\% de significância.

CV = Coeficiente de Variação.

Tabela 7- Médias de produção e qualidade de ovócitos e embriões e taxa de prenhez de todos os grupos, em relação à concentração sérica de progesterona

\begin{tabular}{|c|c|c|c|c|c|}
\hline Grupos & $\begin{array}{l}\text { Concentração de } \\
\mathrm{P}_{4}(\mathrm{ng} / \mathrm{mL})\end{array}$ & $\begin{array}{l}\text { Ovócitos } \\
\text { aspirados }\end{array}$ & $\begin{array}{l}\text { Ovócitos viáveis } \\
(\%)\end{array}$ & $\begin{array}{l}\text { Embriões viáveis } \\
(\%)\end{array}$ & $\begin{array}{l}\text { Taxa de Prenhez } \\
(\%)\end{array}$ \\
\hline G1 & $18,47( \pm 4,97)$ a & $36,73( \pm 23,46) \mathrm{a}$ & $82,93( \pm 11,29) a$ & $40,15( \pm 21,18) a$ & $25,95( \pm 19,27) a$ \\
\hline G2 & $1,53( \pm 1,31) \mathrm{c}$ & $38,33( \pm 24,30) a$ & $84,08( \pm 8,38) a$ & $32,63( \pm 17,31) \mathrm{a}$ & $42,95( \pm 30,06) \mathrm{a}$ \\
\hline G3 & $2,80( \pm 2,40) \mathrm{c}$ & $30,93( \pm 29,53) \mathrm{a}$ & $71,66( \pm 20,08) a$ & $35,40( \pm 30,23) \mathrm{a}$ & $34,64( \pm 34,99) \mathrm{a}$ \\
\hline G4 & $8,40( \pm 1,81) b$ & $51,40( \pm 25,52) \mathrm{a}$ & $83,37( \pm 6,50) a$ & $29,87( \pm 16,17) \mathrm{a}$ & $27,91( \pm 19,77) a$ \\
\hline G5 & $0,95( \pm 0,40) \mathrm{c}$ & $40,20( \pm 18,98) a$ & $80,32( \pm 12,22) a$ & $24,77( \pm 20,19) \mathrm{a}$ & $21,75( \pm 21,43) \mathrm{a}$ \\
\hline $\mathrm{CV}(\%)$ & 42,86 & 62,24 & 15,65 & 66,32 & 84,48 \\
\hline
\end{tabular}

Médias seguidas de letras iguais nas colunas não diferem entre si pelo teste de Tukey com 5\% de significância.

$\mathrm{CV}=$ Coeficiente de Variação.

\section{DISCUSSÃO}

Avaliando-se a importância da presença do CL em um dos ovários e comparando-se com animais sem CL, este trabalho não encontrou diferenças nas variáveis analisadas entre os grupos G4 e G5, que foram de animais não gestantes, com e sem CL, respectivamente.

Os dados, então, discordam dos achados por REIS et al. (2002), que encontraram em novilhas Simental maior número de ovócitos coletados $(7,2 \pm 0,47$ vs $5,7 \pm 0,44, \mathrm{p}<0,05)$, quando o CL está ativo no ovário, e também de REIS et al. (2006), que relataram a presença do CL em vacas Holstein Friesian como fundamental para melhorar as características avaliadas na PIV, em relação aos animais em fase folicular e sem o CL. Esses autores encontraram maior número de ovócitos coletados dos dois ovários $(10,87 \pm 1,01$ vs $7,05 \pm 0,91$, $\mathrm{p}<0,001)$, maior porcentagem de ovócitos viáveis $(62,28 \%$ vs $54,46 \%, \mathrm{p}<0,05)$, mais zigotos que clivaram $(59,03 \%$ vs $45,52 \%, \mathrm{p}<0,05)$ e maior número de embriões aos 7 dias após a FIV $(44,23 \%$ vs $31,48 \%, \mathrm{p}<0,05)$, para os grupos com $\mathrm{CL}$ em relação aos sem CL, respectivamente.
MANJUNATHA et al. (2007) também encontraram, ao trabalharem com ovários oriundos de abatedouro, maiores taxas de clivagem $(57,0 \%$ vs $43,6 \%, \mathrm{p}<0,05)$ e de embriões transferíveis $(19,4 \%$ vs $8,8 \%, \mathrm{p}<0,05)$ a partir de ovários que continham CL, com ou sem folículo dominante (FD), em relação aos ovários sem CL e sem FD, respectivamente.

No entanto, este trabalho concorda com outros autores, quando dizem que o CL em um dos ovários não foi importante para as características de produção in vitro de embriões, quando comparados com animais que não o possuem. MACHATKOVÁ et al. (2000) encontraram mais ovócitos viáveis $(p<0,05)$ em doadoras Holstein sem CL $(8,0 \pm 0,6)$ do que nas doadoras com CL $(3,3 \pm 0,5)$. MACHATKOVÁ et al. (2004) relataram que os melhores ovócitos foram obtidos de ovários em que o CL ainda estava em formação, por volta do dia 3 pós-cio, não sendo importante a presença de um CL funcional para melhorar a qualidade ovocitária. Eles encontraram taxas de produção de embriões de $30,3 \%$ e $14,9 \%(p<0,01)$ em ovários sem e com CL, respectivamente. CHIAN et al. (2002) não encontraram diferença $(\mathrm{p}>0,05)$ em número de ovócitos coletados totais (22,7 com CL vs 26,05 sem 
CL) e nem na produção de embriões $(30,4 \%$ com CL vs 30,2\% sem CL) em taurinos. REIS et al. (2002) não observaram diferenças na porcentagem de ovócitos viáveis $(55 \pm 3 \%$ vs $47 \pm 3 \%, \mathrm{p}>0,05)$ e na produção de embriões $(24 \pm 3 \%$ vs $26 \pm 4 \%$, p>0,05), para os grupos com CL ativo e ausente, respectivamente.

Neste trabalho, para se avaliar a influência local do CL, realizou-se, também, comparação entre os grupos que possuíam corpo lúteo $(\mathrm{G} 1, \mathrm{G} 2, \mathrm{G} 4)$, confrontando-se os resultados do ovário com e sem CL. Observou-se que, nesses grupos, os animais produziram mais embriões de ovócitos oriundos de ovários com CL do que de ovários sem CL (40,93\% vs $31,63 \%, \mathrm{p}<0,05)$. Esses resultados discordam de TAKUMA et al. (2007), que não encontraram diferença $(p>0,05)$ entre a produção do ovário com CL e sem CL, sendo os resultados obtidos, respectivamente, $57,5 \%$ e $65,7 \%$ para taxa de clivagem e $23,6 \%$ e $32,1 \%$ para produção de embriões viáveis. Eles ressaltam que a presença local de um CL no ovário não afeta a dinâmica folicular e nem o desenvolvimento de blastocistos após a OPU. SUGULLE et al. (2008) também não encontraram diferença estatística entre os ovários $(29,0 \%$ com CL vs $30,7 \%$ sem CL) na produção de blastocistos. Quanto aos ovócitos totais coletados neste trabalho, os ovários com e sem CL foram semelhantes $(16,94$ vs 18,00, respectivamente), concordando com SUGULLE et al. (2008), que também não encontraram diferenças estatísticas nessa característica a partir de ovários de abatedouro.

A sincronização de onda folicular para a realização da OPU também foi avaliada. Neste trabalho os grupos G2 e G3 foram submetidos a implantes de $\mathrm{P}_{4}$ com aplicação de $\mathrm{PGF}_{2 \propto}$ no dia zero, sendo que G2 possuía CL e G3 não. Na comparação com os demais, esses dois grupos apresentaram menos ovócitos totais aspirados $(29,40$ e 26,58$)$ que G4 (44,08), que não era submetido ao implante. Quando se comparou G2 com os demais que continham CL (G1 e G4), notou-se que o tratamento hormonal não melhorou nenhuma variável analisada. Quando se comparou G3 com G5, sendo que nenhum possuía CL e G5 não foi submetido ao tratamento hormonal, concluiu-se que G3 $(26,58)$ produziu menos ovócitos totais aspirados que G5 $(40,36)$ e foram semelhantes nas demais características.

Os resultados encontrados neste trabalho concordam com CHAUBAL et al. (2007), em que os protocolos hormonais, à base de progesterona sintética, não melhoraram a resposta folicular e ainda produziram menos blastocistos do que vacas sem o dispositivo de $\mathrm{P}_{4}$, pois os resultados subiram de
$1,33 \pm 0,4$ para $2,89 \pm 0,4$ blastocistos/vaca/sessão de OPU ( $\mathrm{p}<0,05)$, quando não se utilizaram os implantes. Essa conclusão também foi feita por GOODHAND et al. (2000), que não observaram vantagens em sincronizar a onda folicular para a OPU com implante de $\mathrm{P}_{4}$ associado a estradiol $17 \beta$, sendo importante apenas a utilização de FSH para aumentar o número de ovócitos coletados, já que o

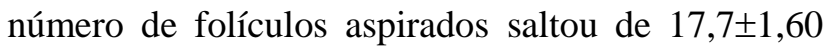
em animais não tratados para 23,6 $\pm 1,97$ em animais tratados com FSH $(p<0,05)$. RAMOS et al. (2010) também não encontraram vantagens na utilização do implante de $\mathrm{P}_{4}$ associado à $\mathrm{BE}$ nem mesmo com a remoção do $\mathrm{FD}$, não havendo incremento na quantidade e qualidade de ovócitos e nem no número de embriões produzidos.

Os resultados deste trabalho discordam dos de PFEIFER et al. (2009), que encontraram em animais mestiços (zebuínos $\times$ taurinos), submetidos a tratamento com $\mathrm{P}_{4}$ exógena, maior número de ovócitos totais $(6,80$ vs $3,40, \mathrm{p}<0,05)$, mais ovócitos viáveis $(64,85 \%$ vs $46,60 \%, \mathrm{p}<0,05)$ e mais blastocistos $(1,05$ vs $0,4, \mathrm{p}<0,05)$ produzidos por OPU do que o grupo sem $\mathrm{P}_{4}$ exógena, respectivamente.

No entanto, BACELAR et al. (2010) submeteram novilhas Nelore ao mesmo protocolo hormonal deste estudo e obtiveram média de 8,07 ovócitos totais aspirados e ainda 78,76\% de ovócitos viáveis, enquanto neste trabalho conseguiu-se maior quantidade de ovócitos totais (média de 27,99), mas semelhante porcentagem de ovócitos viáveis (média de $80,21 \%$ ).

BACELAR et al. (2010) afirmam que a ausência de CL no momento da aspiração folicular apresenta vários aspectos favoráveis, dentre os quais a maior facilidade de localização e punção dos folículos, bem como a redução da perfusão vascular, com menor captação de sangue, justificando a utilização do luteolítico.

Quanto à categoria de vacas gestantes, TAKUMA et al. (2010) concluíram que estas tiveram maiores taxas de clivagem $\mathrm{e}$ desenvolvimento de blastocistos que vacas não gestantes $(p<0,05)$, mas com semelhantes quantidades e qualidades de ovócitos coletados. Neste trabalho, as gestantes não produziram mais blastocistos e ainda produziram menos ovócitos totais aspirados que vazias e cíclicas, concordando com DOMÍNGUEZ (1995), que observou menos folículos aptos à aspiração em vacas gestantes do que nas vazias e cíclicas.

Ao se avaliar a proporção do sexo dos fetos, notou-se que não houve predomínio de um grupo sobre os demais em relação a um dos sexos e nem de 
um sexo dentro de cada grupo individualmente Esses fatos reforçam o entendimento de que a definição do sexo independe do estado fisiológico da fêmea ou do ovário em que se originou o ovócito. Esses dados discordam da maioria das produções in vitro com sêmen convencional, como defendem AVERY et al. (1991) e GUTIERREZ-ADÁN et al. (2001), que encontraram maiores proporções de machos $(70 \%)$ na PIV e CAMARGO et al. (2010) com 76,9\%; no entanto, concorda com MACHADO et al. (2009), em que a proporção de machos e fêmeas manteve-se em 1:1, mesmo utilizando-se diferentes touros e diferentes tratamentos, na preparação do sêmen para a FIV.

\section{CONCLUSÕES}

A partir de estudo sobre fêmeas bovinas doadoras de ovócitos da raça Nelore conclui-se que a aspiração de ovócitos de vacas com a presença de CL mostrou que os ovários com CL produziram mais embriões viáveis aos sete dias pós-fecundação in vitro, do que os sem CL; a produção de embriões provenientes de ovócitos de ovários sem CL em vacas gestantes foi maior, talvez pela maior concentração de $\mathrm{P}_{4}$ circulante; a utilização de protocolos hormonais à base de progestágeno por cinco dias para a aspiração folicular das doadoras não apresentou benefícios em relação à sua não utilização; a aplicação de $\mathrm{PGF}_{2 \propto}$ em vacas com CL, submetidas a implante de progestágeno, não melhorou a quantidade de ovócitos totais coletados, durante a punção folicular superficial dos ovários; a taxa de prenhez das receptoras não foi influenciada pela situação fisiológica da doadora dos ovócitos, em programas de PIV; a proporção entre os sexos dos fetos não dependeu da situação fisiológica da doadora, quando o sêmen utilizado na FIV foi convencional. Portanto, o melhor critério de escolha de doadoras Nelore ou de manejo para programas de PIV é o conhecimento individual de cada animal ao longo das seções de OPU.

\section{AGRADECIMENTOS}

Os autores agradecem ao laboratório Biovitro (Uberaba - MG), à empresa Nova Consultoria Reprodutiva Animal e Calixto Assessoria Reprodutiva.

\section{REFERÊNCIAS}

AVERY, B.; MADISON, V.; GREVE, T. Sex and development in bovine in vitro embryo production. Theriogenology, v. 35, n. 5, p. 953-963, 1991.
BACELAR, D.; MAX, M.C.; PADILHA, L.C.; BARREIROS, T.R.R.; SENEDA, M.M. Incremento na obtenção de oócitos em novilhas Nelore (Bos taurus indicus) tratadas com progesterona injetável e benzoato de estradiol. Semina: Ciências Agrárias, Londrina, v. 31, n. 1, p. 163-172, 2010.

BAVISTER, B.D.; HELLEKANT, T.A.R.; PINYOPUMMINTR, T. Development of in vitro matured/in vitro fertilized bovine embryos into morulae and blastocysts in defined culture media. Theriogenology, v. 37, n. 1, p. 127-146, 1992.

BIASE, N.G.; FERREIRA, D.F. Comparações múltiplas e testes simultâneos para parâmetros binomiais de $K$ populações independentes. Revista Brasileira de Biometria, v. 27, n. 3, p. 301-323, 2009.

BLONDIN, P.; BOUSQUET, D.; TWAGIRAMUNGU, H.; BARNES, F.; SIRARD, M.A. Manipulation of follicular development to produce developmentally competent bovine oocytes. Biology of Reproduction, v. 66, n. 1, p. 38-43, 2002.

CAMARGO, L.S.; FREITAS, C.; de SÁ, W. F.; de MORAES FERREIRA, A.; SERAPIÃO R.V.; VIANA, J.H. Gestation length, birth weight and offspring gender ratio of in vitro-produced Gyr (Bos indicus) cattle embryos. Animal Reproduction Science, v. 120, n. 1-4, p. 10-15, 2010.

CHAUBAL, S.A.; FERRE, L.B.; MOLINA, J.A.; FABER, D.C.; BOLS, P.E.; REZAMAND, P.; TIAN, X.; YANG, X. Hormonal treatments for increasing the oocyte and embryo production in an OPU-IVP system. Theriogenology, v. 67, n. 4, p. 719-728, 2007.

CHIAN, R.C.; CHUNG, J.T.; DOWNEY, B.R.; TAN, S.L. Maturational and developmental competence of immature oocytes retrieved from bovine ovaries at different phases of folliculogenesis. Reproductive Biomedicine Online, v. 4, n. 2, p. 127-132, 2002.

DE LOOS, F.; KASTRUP, P.; VAN MAURIK, P.; VAN BENEDEN, T.H.; KRUIP, T.A. Heterologous cell contacts and metabolic coupling in bovine cumulus oocyte complexes. Molecular Reproduction and Development, v. 28, n. 3, p. 255-259, 1991.

DOMÍNGUEZ, M.M. Effects of body condition, reproductive status and breed on follicular population and oocyte quality in cows. Theriogenology, v. 43, n. 8 , p. 1405-1418, 1995.

GOODHAND, K.L.; STAINES, M.E.; HUTCHINSON, J.S.; BROADBENT, P.J. In vivo oocyte recovery and in vitro embryo production from bovine oocyte donors treated with progestagen, oestradiol and FSH. Animal Reproduction Science, v. 63, n. 3-4, p. 145-158, 2000.

GUTIÉRREZ-ADÁN, A.; LONERGAN, P.; RIZOS, D.; WARD, F.A.; BOLAND, M.P.; PINTADO, B.; FUENTE, J. Effect of the in vitro culture system on the kinetics of blastocyst development and sex ratio of bovine embryos. Theriogenology, v. 55, n. 5, p. 1117-1126, 2001. 
HOLM, P.; BOOTH, P.J.; SCHMIDT, M.H.; GREVE, T.; CALLESEN, H. High bovine blastocyst development in a static in vitro production system using sofaa medium supplemented with sodium citrate and myo-inositol with or without serum-proteins. Theriogenology, v. 52, n. 4, p. 683-700, 1999.

MACHADO, G.M.; CARVALHO, J.O.; FILHO, E.S.; CAIXETA, E.S.; FRANCO, M.M.; RUMPF, R.; DODE, M.A. Effect of Percoll volume, duration and force of centrifugation, on in vitro production and sex ratio of bovine embryos. Theriogenology, v. 71 , n. 8, p. 12891297, 2009.

MACHATKOVÁ, M.; JOKESOVÁ, E.; HORKY, F.; KREPELOVÁ, A. Utilization of the growth phase of the first follicular wave for bovine oocyte collection improves blastocyst production. Theriogenology, v. 54 , n. 4, p. 543-550, 2000.

MACHATKOVÁ, M.; JOKESOVÁ, E.; PETELÍKOVÁ, J.; DVORÁCEK, V. Developmental competence of bovine embryos derived from oocytes collected at various stages of the estrous cycle. Theriogenology, v. 45, n. 4, p. 801-810, 1996.

MACHATKOVÁ, M.; KRAUSOVÁ, K.; JOKESOVÁ, E.; TOMANEK, M. Developmental competence of bovine oocytes: effects of follicle size and the phase of follicular wave on in vitro embryo production. Theriogenology, v. 61, n. 3, p. 329-335, 2004.

MANJUNATHA, B.M.; GUPTA, P.S.; RAVINDRA, J.P.; DEVARAJ, M.; RAMESH, H.S.; NANDI, S. In vitro developmental competence of buffalo oocytes collected at various stages of the estrous cycle. Theriogenology, v. 68, n. 6, p. 882-888, 2007.

MEINTJES, M.; BELLOW, M.S.; BROUSSARD, J.R.; PAUL, J.B.; GODKE, R.A. Transvaginal aspiration of oocytes from hormone-treated pregnant beef for in vitro fertilization. Journal of Animal Science, v. 73, n. 4, p. 967-974, 1995.

PARRISH, J.J.; SUSKO-PARRISH, J.L.; LEIBFRIEDRUTLEDGE, M.L.; CRITSER, E.S.; EYESTONE, W.H.; FIRST, N.L. Bovine in vitro fertilization with frozenthawed semen. Theriogenology, v. 25, n. 4, p. 591-600, 1986.

PFEIFER, L.F.M.; SARTORI, R.; PIVATO, I.; RUMPF, R.; NOGUEIRA, G.P.; XAVIER, E.G.; DIONELLO,
N.J.L.; CORRÊA, M.N. Effect of circulating progesterone on in vitro developmental competence of bovine oocytes. Animal Reproduction, v. 6, n. 3, p. 473-480, 2009.

RAMOS, A.F.; RUMPF, R.; CÂMARA, J.U.; MOLLO, M.R.; PIVATO, I.; MARQUES, A.P.Jr.; SARTORI, R. Effect of follicular wave synchronization on in vitro embryo production in heifers. Animal Reproduction Science, v. 117, n. 3-4, p. 201-207, 2010.

REIS, A.; METELO, R.; SANTOS, P.; SILVA, F. M. Efeito da estrutura ovárica e da idade de bovinos da raça Holstein Friesian na quantidade e qualidade de ovócitos e de embriões produzidos in vitro. Brazilian Journal of Veterinary Research and Animal Science, v. 43, n. 5, p. 629-636, 2006.

REIS, A.; STAINES, M.E.; WATT, R.G.; DOLMAN, D.F.; McEVOY, T.G. Embryo production using defined oocyte maturation and zygote culture media following repeated ovum pick-up (OPU) from FSH-stimulated Simmental heifers. Animal Reproduction Science, v. 72, n. 3-4, p. 137-151, 2002.

SAUVÉ, R. Ultrasound guided follicular aspiration and in vitro fertilization. Arquivos da Faculdade de Veterinaria UFRGS, v. 26, n. 1, p. 141-155, 1998.

SCHAMS, D.; BERISHA, B. Regulation of Corpus Luteum Function in Cattle - an Overview. Reproduction in Domestic Animals, v. 39, n. 4, p. 241-251, 2004.

SUGULLE, A.H.; DOCHI, O.; KOYAMA, H. Developmental competence of bovine oocytes selected by Brilliant Cresyl Blue Staining: Effect of the presence of corpus luteum on embryo development. Journal of Mammalian Ova Research, v. 25, n. 1, p. 50-55, 2008.

TAKUMA, T.; OTSUBO, T.; KUROKAWA, Y.; OTOI, T. Effects of the corpus luteum within the ovary on the follicular dynamics after follicular aspiration and on the developmental competence of aspired oocytes. Reproduction, Fertility and Development, v. 19, n. 1, p. 324, 2007.

TAKUMA, T.; SAKAI, S.; EZOE, D.; ICHIMARU, H.; JINNOUCHI, T.; KAEDEI, Y.; NAGAI, T.; OTOI, T. Effects of season and reproductive phase on the quality, quantity and developmental competence of oocytes aspirated from Japanese black cows. The journal of reproduction and development, v. 56, n. 1, p. 55-59, 2010. 